\title{
Feasibility and effectiveness of daily temperature screening to detect COVID-19 in a prospective cohort at a large public university
}

Shelley N. Facente ${ }^{1,2^{*}}$, Lauren A. Hunter ${ }^{1}$, Laura J. Packel', Yi Li ${ }^{1}$, Anna Harte ${ }^{3}$, Guy Nicolette ${ }^{3}$, Shana McDevitt ${ }^{4}$, Maya Petersen ${ }^{1}$ and Arthur L. Reingold ${ }^{1}$

\begin{abstract}
Background: Many persons with active SARS-CoV-2 infection experience mild or no symptoms, presenting barriers to COVID-19 prevention. Regular temperature screening is nonetheless used in some settings, including university campuses, to reduce transmission potential. We evaluated the potential impact of this strategy using a prospective university-affiliated cohort.

Methods: Between June and August 2020, 2912 participants were enrolled and tested for SARS-CoV-2 by PCR at least once (median: 3, range: 1-9). Participants reported temperature and symptoms daily via electronic survey using a previously owned or study-provided thermometer. We assessed feasibility and acceptability of daily temperature monitoring, calculated sensitivity and specificity of various fever-based strategies for restricting campus access to reduce transmission, and estimated the association between measured temperature and SARS-CoV-2 test positivity using a longitudinal binomial mixed model.

Results: Most participants (70.2\%) did not initially have a thermometer for taking their temperature daily. Across 5481 total person months, the average daily completion rate of temperature values was 61.6\% (median: 67.6\%, IQR: 41.8-86.2\%). Sensitivity for SARS-CoV-2 ranged from 0\% (95\% Cl 0-9.7\%) to 40.5\% (95\% Cl 25.6-56.7\%) across all strategies for self-report of possible COVID-19 symptoms on day of specimen collection, with corresponding specificity of $99.9 \%$ (95\% Cl 99.8-100\%) to $95.3 \%$ (95\% Cl 94.7-95.9\%). An increase of $0.1^{\circ} \mathrm{F}$ in individual mean body temperature on the same day as specimen collection was associated with 1.11 increased odds of SARS-CoV-2 positivity (95\% Cl 1.06-1.17).
\end{abstract}

\footnotetext{
* Correspondence: sfacente@berkeley.edu

${ }^{1}$ School of Public Health, Division of Epidemiology and Biostatistics,

University of California, Berkeley, 2121 Berkeley Way \# 5302, Berkeley, CA

94720, USA

${ }^{2}$ Facente Consulting, Richmond, CA, USA

Full list of author information is available at the end of the article
}

(C) The Author(s). 2021 Open Access This article is licensed under a Creative Commons Attribution 4.0 International License, which permits use, sharing, adaptation, distribution and reproduction in any medium or format, as long as you give appropriate credit to the original author(s) and the source, provide a link to the Creative Commons licence, and indicate if changes were made. The images or other third party material in this article are included in the article's Creative Commons licence, unless indicated otherwise in a credit line to the material. If material is not included in the article's Creative Commons licence and your intended use is not permitted by statutory regulation or exceeds the permitted use, you will need to obtain permission directly from the copyright holder. To view a copy of this licence, visit http://creativecommons.org/licenses/by/4.0/. The Creative Commons Public Domain Dedication waiver (http://creativecommons.org/publicdomain/zero/1.0/) applies to the data made available in this article, unless otherwise stated in a credit line to the data. 


\begin{abstract}
Conclusions: Our study is the first, to our knowledge, that examines the feasibility, acceptability, and effectiveness of daily temperature screening in a prospective cohort during an infectious disease outbreak, and the only study to assess these strategies in a university population. Daily temperature monitoring was feasible and acceptable; however, the majority of potentially infectious individuals were not detected by temperature monitoring, suggesting that temperature screening is insufficient as a primary means of detection to reduce transmission of SARS-CoV-2.
\end{abstract}

Keywords: COVID-19, SARS-CoV-2, Fever, Temperature monitoring, Thermometer, Detection, Screening

\section{Background}

SARS-CoV-2 is a novel coronavirus that causes coronavirus disease 2019, otherwise known as COVID-19 [1]. One of the most challenging features of the COVID-19 epidemic to date is considerable pre-symptomatic [2] and asymptomatic transmission [3, 4], currently estimated to comprise anywhere from 6 to $41 \%$ of infectious individuals [5]; many other individuals may experience only mild symptoms. This presents barriers to epidemic control by impeding rapid isolation of cases, and makes it necessary to develop nuanced screening approaches that will both limit infectious exposure and be a useful trigger for SARS-CoV-2 testing. Accordingly, a strong desire to have students and employees return in person to school or work has driven workplaces, businesses, and colleges to look for methods to rapidly assess risk of infection and prevent entry for those who are possibly infectious to others.

One common strategy to prevent transmission has been temperature checks, which have increased in popularity as a non-invasive measure to rapidly screen individuals for elevated body temperature (i.e., fever). Temperature screening has been used during other global outbreaks, including the severe acute respiratory syndrome (SARS) outbreak in 2003, the H1N1 influenza epidemic in 2009 [6], and recent major Ebola virus disease outbreaks in Sub-Saharan Africa in 2014 and 2018 [7]. However, multiple studies have found low sensitivity or specificity of temperature monitoring during these prior epidemics $[8,9]$, even in cases where fever was a very common symptom among people with the disease in question $[6,10,11]$. Large infrared fever screening systems or no-contact temperature screening at building entrances [12] and hospital entryways [13] and wearable devices to continuously monitor individual temperature [14] have all been widely employed in an attempt to prevent the spread of SARS-CoV-2, yet limited evidence exists concerning the sensitivity and specificity of these approaches for the current pandemic [15], especially on a university campus. Of note, the United States Food and Drug Administration (FDA) released a statement in June 2020 noting that non-contact temperature assessment devices "are not effective if used as the only means of detecting a COVID-19 infection" [16].
Nonetheless, a number of college campuses are now implementing systems that require students, faculty, and staff to attest that they are free of symptoms, and/or are afebrile before coming to campus [17-21]. These policies almost universally rely on dichotomous temperature cutoffs for fever, e.g. temperature $\geq 100.4^{\circ} \mathrm{F}$, in alignment with the CDC guidelines [22]. Such strategies have numerous pitfalls, including reliance on an outdated sense of "normal" body temperature [23], disregard of the effect of time of day [24] and ambient temperature on body temperature [25], disregard of numerous studies that have found meaningful variation in normal body temperature between individuals [26, 27], and incentives to not voluntarily disclose symptoms in order to preserve access to work spaces and therefore safeguard career and financial stability [28].

Given the rapid increase in reliance on temperaturebased strategies to restrict campus access for prevention of COVID-19 spread, we aimed to assess the feasibility, acceptability, and effectiveness of temperature monitoring and other fever-based strategies to prevent spread of SARS-CoV-2 in a longitudinal cohort of 2916 universityaffiliated students and employees, known as the Berkeley COVID-19 Safe Campus Initiative.

\section{Methods}

\section{Study setting and population}

Any students, faculty, or staff (including essential workers) who were affiliated with the University of California (UC), Berkeley and were living in Berkeley or the surrounding counties during the summer of 2020 were eligible to enroll in the Safe Campus cohort. UC Berkeley is an elite public university in Northern California with 42,347 students enrolled in the 2020-2021 school year, 30,799 of whom were undergraduates. SARS-CoV-2 test positivity on campus peaked at $4.2 \%$ the week of June 29, 2020 during a small outbreak among students, but from June 1 through August 18 of that year (the study period) there were 135 positive PCR tests out of 10,090 total tests conducted (1.3\% positivity). Students, faculty, and staff of UC Berkeley were recruited via campus email blasts and sharing via relevant listservs, flyering in congregate student living situations (i.e. Greek housing and co-operatives), and word of 
mouth from June 1st through July 17th. Interested individuals were sent to a study website where they could complete a brief screening survey to determine eligibility. Enrollment was completed on a rolling basis during the recruitment period. This observational prospective cohort is reported here according to STROBE guidelines [29].

\section{Survey measures and temperature assessment}

Participants provided information about thermometer availability during a baseline survey, and were told that if they did not already own a thermometer they would be provided with a digital oral thermometer when they reported to University Health Services for baseline specimen collection. Participants were instructed to measure their temperature in the morning, before leaving the house (if applicable), and to follow manufacturer's instructions for their thermometer, including waiting a full 60 seconds before recording the temperature reading if using a study-provided thermometer. They were asked to report quantitative temperature and any symptoms potentially related to COVID-19 (including "feeling feverish") on electronic daily surveys via a HIPAAcompliant version of Research Electronic Data Capture (REDCap) [30, 31], from the day after they completed the baseline survey through study close August 18th. Participants were prompted each morning to complete their daily survey via e-mail or text message, depending on their preference, and student participants were provided with a $\$ 50$ incentive for completing their baseline specimen collection and 10 daily surveys in order to encourage habit formation [32, 33]. Beginning August 1st participants were sent a message requesting them to complete an endline survey that included questions about feasibility and acceptability of recording their temperature each day.

\section{PCR testing}

All participants were asked to come to University Health Services (UHS) on the UC Berkeley campus for an oral/ nasal midturbinate swab for SARS-CoV-2 polymerase chain reaction (PCR) testing at the start of the study, and participants who were students or essential workers were also asked to return for an endline PCR test in early August. Participants were also offered PCR testing on-demand at any time during the study, and were specifically asked to come to UHS for a PCR test if they reported a temperature of $\geq 100.4^{\circ} \mathrm{F}$, said they were "feeling feverish," reported other specific symptoms (dry cough, coughing up mucus, unusual pain or pressure in the chest, difficulty breathing, shortness of breath, unexplained trouble thinking or concentrating, or loss of sense of taste or smell), or reported a specific potential exposure to COVID-19. Participants were PCR tested a minimum of once and a maximum of 9 times during the study, with a median of 3 tests per person [34]. PCR tests were all conducted at UC Berkeley's Innovative Genomics Institute.

\section{Statistical analysis}

We assessed potential impact of temperature-based screening on transmission of SARS-CoV-2 through calculating sensitivity, specificity, positive predictive value (PPV), and negative predictive value (NPV) for a range of strategies for detecting SARS-CoV-2 infection, including temperature greater than a range of thresholds for "fever" ( $\geq 100.4^{\circ} \mathrm{F}, \geq 99.7^{\circ} \mathrm{F}, \geq 98.7^{\circ} \mathrm{F}$ ) on the day of specimen collection, temperature $\geq 98.7^{\circ} \mathrm{F}$ on the day of specimen collection or on any day up to 3 days prior to collection, a qualitative assessment of "feeling feverish" as a symptom, and being "symptomatic," which for purposes of this analysis included reporting dry cough, coughing up mucus, fever, sweats, chills, sore throat, difficulty breathing, wheezing, shortness of breath, loss of sense of taste, loss of sense of smell, or at least three symptoms from a list of 35 symptoms potentially associated with COVID-19 (see Supplemental Table 1). The range of temperature thresholds were chosen to include the CDC threshold for fever during the pandemic $\left(\geq 100.4^{\circ} \mathrm{F}\right)$ [22], anything exceeding the commonly understood "normal" human body temperature (> $98.6^{\circ} \mathrm{F}$ ), and - as middle ground between those two anything greater than $1^{\circ} \mathrm{F}$ above "normal" $\left(\geq 99.7^{\circ} \mathrm{F}\right)$. The results of PCR testing were used as the gold standard for determining "true" SARS-CoV-2 positivity or negativity in relation to these performance measures, and $95 \%$ confidence intervals (CIs) were calculated using the Clopper Pearson method [35] for sensitivity and specificity and asymptotic standard logit intervals [36] for the predictive values, using the $b d p v$ package within $\mathrm{R}$ [37]. Adjusted logit intervals were used to compute intervals in the case where the predictive value was zero. A Fisher's Exact Test for independence was used to test the null hypothesis that there was no difference in SARS-CoV-2 infection for people who would have been prohibited entry to campus as a result of screening for fever using the strategy in question, and those who would be permitted entry to campus.

We used a longitudinal binomial mixed model with a random intercept for each participant to examine the association between individually mean-centered quantitative temperature and SARS-CoV-2 PCR result. This association was assessed using a simple model with no additional covariates, as well as a model controlling for mean-centered local ambient temperature on the day body temperature was recorded, and age of the participant. 


\section{Results}

By the close of enrollment on July 17th, 2916 participants had enrolled and provided a specimen for at least one PCR test. Recruitment was not begun for faculty and staff until much later in the study period; thus 74.7\% of participants were students. All participants with at least one valid PCR test result who reported not having tested positive for SARS-CoV-2 prior to enrollment were included in this analysis $(n=2912)$. Due to rolling enrollment with a fixed end date, participants were enrolled for different lengths of time, ranging from 28 to 77 days between baseline specimen collection and $\mathrm{Au}-$ gust 18th (median: 54 days, IQR: 43-64 days).

\section{Feasibility of daily thermometer usage}

At enrollment, $70.3 \%$ of participants did not have access to a thermometer for daily use at home and needed to be provided one by the study. This was particularly true for students (76.7\%), participants under age 30 (77.2\%), and Black (80.4\%), Asian/Pacific Islander (77.4\%) and Latinx (76.3\%) participants (Table 1). The majority (70.5\%) of participants who had their own thermometer had an oral thermometer, followed by $12.8 \%$ with a forehead thermometer, $7.8 \%$ with an ear thermometer, $4.1 \%$ with a no-touch thermometer, and the remainder with other types. All participants who received a thermometer through the study used an oral thermometer. Overall, participants had a mean temperature of $97.6^{\circ} \mathrm{F}$ over the course of the study (IQR: 97.1-98.2 ${ }^{\circ} \mathrm{F}$ ). This mean temperature was deemed reasonable, given that participants were instructed to measure their temperature in the morning, when mean body temperatures have been found to generally be below the typically considered "normal" temperature, $98.6^{\circ} \mathrm{F}$ [23].

Participants reported their temperature measurement a median of $67.6 \%$ (IQR: $41.8-86.2 \%$ ) of the total days they were enrolled (Fig. 1, panel A), and more than $30 \%$ of participants $(n=885)$ recorded the temperature every day they completed at least some of the daily survey (Fig. 1, panel B).

\section{Acceptability of daily temperature monitoring}

During the endline survey, participants were asked about the acceptability of daily temperature monitoring, and $92.9 \%$ reported it to be acceptable $(n=735)$ or totally acceptable $(n=1734)$. Only 35 participants out of 2659

Table 1 Characteristics of study participants, by personal thermometer availability

\begin{tabular}{|c|c|c|c|c|}
\hline \multirow{2}{*}{$\begin{array}{l}\text { Characteristic } \\
\text { Total }\end{array}$} & & \multirow{2}{*}{$\begin{array}{l}\text { Total participants } \\
2912\end{array}$} & \multicolumn{2}{|c|}{$\begin{array}{l}\text { Needed a thermometer } \\
\#(\%)\end{array}$} \\
\hline & & & 2026 & (69.6\%) \\
\hline \multirow[t]{3}{*}{ Cohort } & Student & 2174 & 1646 & (75.7\%) \\
\hline & Essential worker & 268 & 165 & $(61.6 \%)$ \\
\hline & Faculty/staff & 470 & 215 & $(45.7 \%)$ \\
\hline \multirow[t]{5}{*}{ Age (years) } & $<21$ & 881 & 730 & $(82.9 \%)$ \\
\hline & $22-29$ & 1085 & 787 & (72.5\%) \\
\hline & $30-39$ & 446 & 258 & $(57.8 \%)$ \\
\hline & $40-49$ & 195 & 103 & $(52.8 \%)$ \\
\hline & $50+$ & 279 & 148 & $(53.0 \%)$ \\
\hline \multirow[t]{3}{*}{ Gender identity } & Woman $^{a}$ & 1634 & 1101 & (67.4\%) \\
\hline & $\operatorname{Man}^{\mathrm{b}}$ & 1171 & 862 & $(73.6 \%)$ \\
\hline & Non-binary & 50 & 37 & (74.0\%) \\
\hline \multirow[t]{6}{*}{ Race/Ethnicity ${ }^{c}$} & Black & 102 & 82 & $(80.4 \%)$ \\
\hline & Latinx & 395 & 301 & (76.2\%) \\
\hline & Asian/Pacific Islander & 825 & 637 & (77.2\%) \\
\hline & Native American/American Indian & 38 & 26 & $(68.4 \%)$ \\
\hline & White & 1802 & 1180 & $(65.5 \%)$ \\
\hline & Other & 91 & 68 & $(74.7 \%)$ \\
\hline \multirow[t]{2}{*}{$\mathrm{PCR}^{\mathrm{d}}$ results } & All negative & 2852 & 1980 & $(69.4 \%)$ \\
\hline & At least one positive & 60 & 46 & $(76.7 \%)$ \\
\hline
\end{tabular}

\footnotetext{
${ }^{a}$ Category likely includes some participants who are transwomen

${ }^{b}$ Category likely includes some participants who are transmen

c Categories are not mutually exclusive

${ }^{\mathrm{d}}$ PCR $=$ Polymerase Chain Reaction
} 

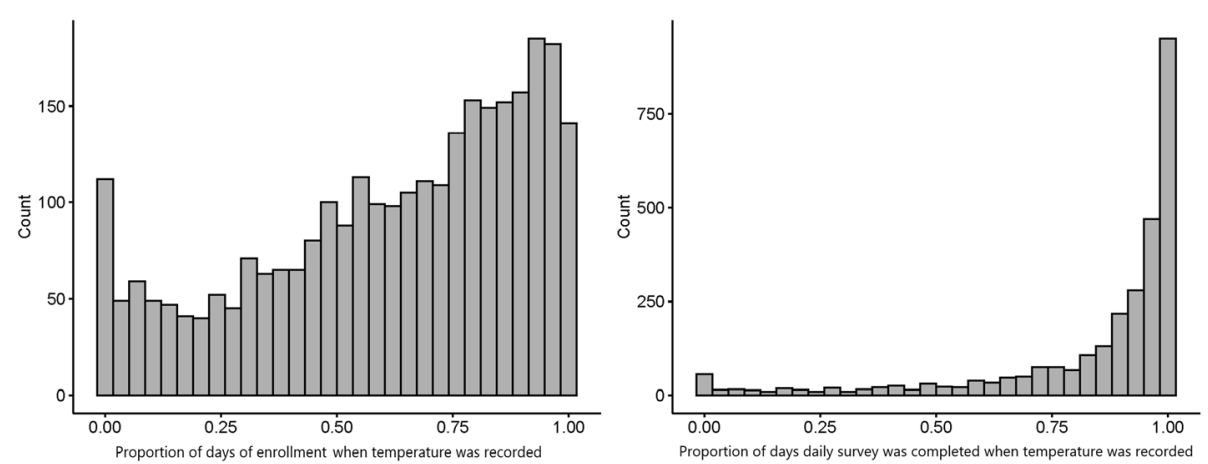

Fig. 1 Participant count of the proportion of days quantitative temperature was recorded via the daily survey, per total days of enrollment (A) and total days for which the daily survey was at least partially completed (B)

who took the endline survey (1.3\%) found it to be unacceptable. When asked how likely they would be to continue to comply with daily temperature monitoring if UC Berkeley used this study as a model for campus-wide practice, 1079 people (40.5\%) said they were "extremely likely" to continue, and 1027 (38.6\%) said they would be "likely" to continue. Only 291 people (10.9\%) said they were "unlikely" or "extremely unlikely" to comply with a request to continue monitoring their temperature daily. However, when asked about the "most difficult" aspect of their study participation at endline, daily temperature monitoring was the most frequently selected study component: 766 people (36.1\%) chose daily temperature monitoring, compared to $17.6 \%$ who chose having oral/ nasal swabs collected for PCR testing, the next most common answer (Supplemental Table 2).

\section{Effectiveness for detection of SARS-CoV-2 infection}

More than a third (35\%) of the 60 participants in our study who tested positive for SARS-CoV-2 did so at their baseline collection; as a result, positive test results were preceded by a median of six recorded temperatures (range 1-55, IQR 2-21). In comparison, negative tests were preceded by a median of 13 recorded temperatures (range 1-76, IQR 1-31).

Thirty-six (60.0\%) of 60 positive tests for SARS-CoV-2 by PCR were preceded by a participant reported temperature the same day; 37 (61.7\%) were preceded by at least one reported temperature in the 3 days prior to specimen collection.

Mean temperatures among participants testing positive ranged from $96.7^{\circ} \mathrm{F}-99.0^{\circ} \mathrm{F}$ during the study (Fig. 2). Among the 56 participants who tested positive for SARS-CoV-2 and recorded their temperature at least once during the study period, only 4 participants measured at least one temperature above $100^{\circ} \mathrm{F}$ at any time, and a temperature $\geq 100^{\circ} \mathrm{F}$ was measured only 10 times out of 1637 total measurements (0.6\%) taken throughout the study among those testing positive. This is notable given the $\mathrm{CDC}$-suggested threshold of $100.4^{\circ} \mathrm{F}$ as evidence of fever [22].

Sensitivity for detecting SARS-CoV-2 infection ranged from $0 \%(95 \%$ CI $0.0-9.7 \%)$ to $30.6 \%$ (95\% CI $16.3-$ $48.1 \%)$ for the strategies using various thresholds for fever on the same day as specimen collection, among the 4330 people who recorded a temperature the same day as specimen collection (Table 2). Positive predictive value for these temperature thresholds ranged from $0 \%$ (95\% CI $0.0-59.4 \%$ ) to a high of $21.4 \%$ (95\% CI $7.4-$ $48.6 \%)$, and negative predictive value was $99.2 \%$ (95\% CI $99.1-99.3 \%)$ to $99.4 \%(99.2-99.5 \%)$.

Sensitivity predictably increased as the threshold for fever was lowered, with a resulting trade-off in specificity. Self-reported qualitative symptoms ("feeling feverish") had a higher sensitivity (19.0, 95\% CI 8.6-34.1\%) than either of the quantitative fever thresholds often used in practice (temperature $\geq 100.4^{\circ} \mathrm{F}$ or $\geq 99.7^{\circ} \mathrm{F}$ ), and comparable specificity of $99.7 \%$ (95\% CI $99.5-99.8 \%$ ), compared to a specificity of $99.9 \%$ (95\% CI $99.8-100 \%)$ for the $\geq 100.4^{\circ} \mathrm{F}$ threshold and $99.7 \%$ (95\% CI 99.599.9\%) for the $\geq 99.7^{\circ} \mathrm{F}$ threshold.

Participants also reported information about qualitative fever symptoms the same day as their PCR specimen collection an additional 1126 times, compared to quantitative temperature measurements. As would be expected, self-report of symptoms potentially indicating SARS-CoV-2 infection (including but not limited to fever) yielded the greatest sensitivity $(40.5$, 95\% CI $25.6-$ $56.7 \%$, with specificity of $95.3,95 \%$ CI $94.7-95.9 \%)$, but had a positive predictive value of only $6.3 \%$ (4.4-9.0\%), well below that of self-reported "feeling feverish" alone (32.0, 95\% CI 17.8-50.9\%).

There was an association between temperature readings and SARS-CoV-2 PCR result, with an increase of $0.1^{\circ} \mathrm{F}$ above individual mean body temperature the day of the PCR specimen collection associated with a 1.11 


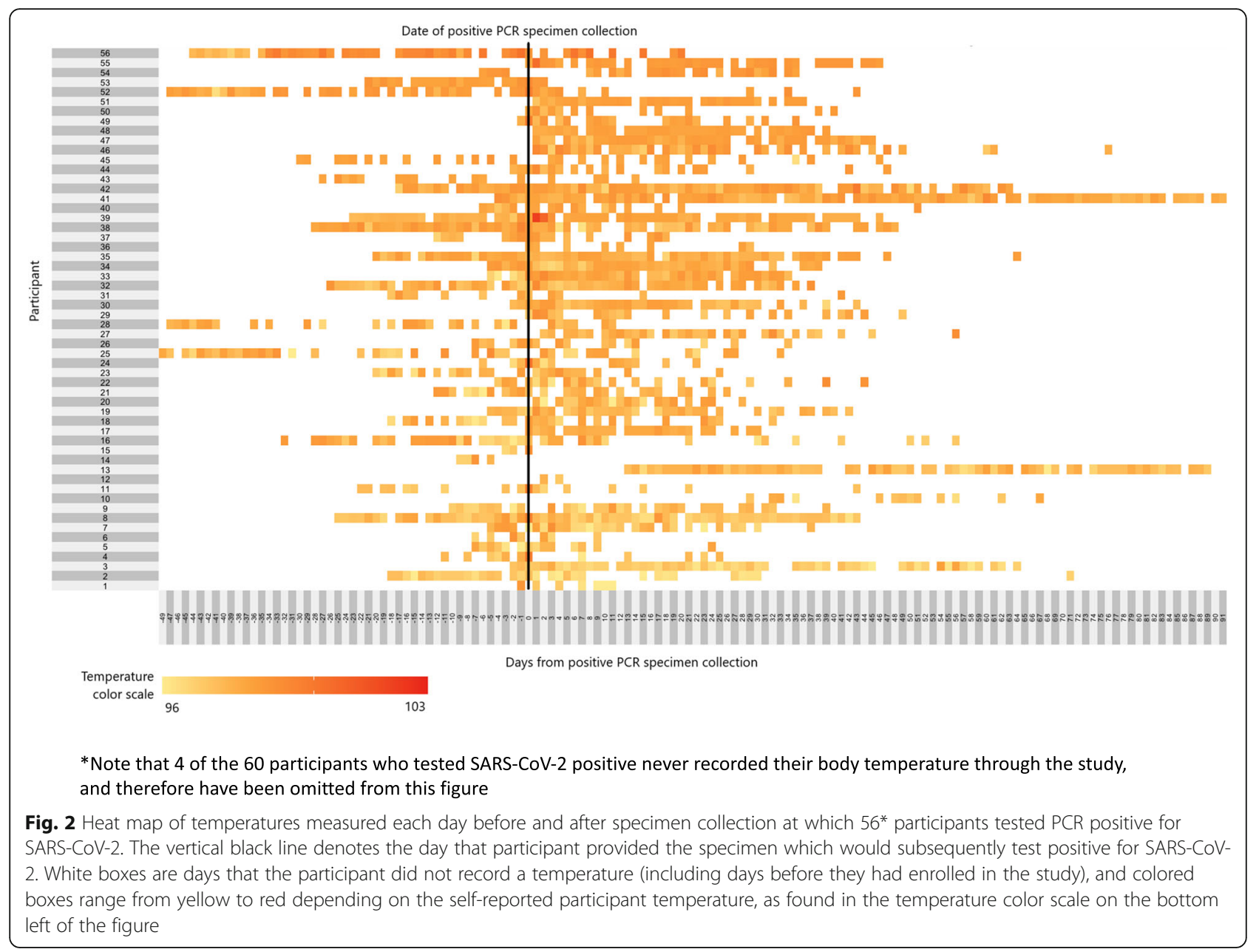

increased odds of SARS-CoV-2 positivity (95\% CI 1.061.17), which did not change when controlling for local ambient temperature and age.

\section{Discussion}

We found that daily temperature monitoring to screen for SARS-CoV-2 infection was acceptable to a wide variety of people affiliated with a large public university. While only $30.4 \%$ of participants recorded their temperature every day they completed at least some of the daily survey, on average participants completed 40 daily surveys (median: 40, IQR: 30-53) during the study period, with 77 participants taking 70 or more daily surveys during a study period that was 78 days from day 1 of rolling enrollment through study end. Particularly among students (who were enrolled for substantially longer than non-students on average), the number of surveys completed per day started to decrease in early August (see Supplemental Figures 1 and 2). It is expected that many people would eventually look for efficiencies in their study participation, including frequently completing a very brief symptoms survey without taking the extra step to take their temperature and record the quantitative reading.

We also found daily temperature monitoring to be feasible for participants; however, almost 3 out of 4 people, particularly students, did not already own thermometers, and purchasing and disseminating thermometers of sufficient quality during a global pandemic proved nearly impossible: taken together, these thermometers cost over $\$ 18,200$ just to cover the needs of our study participants, calling into question the feasibility of this strategy on a campus-wide level. This highlights the challenges of accessing this type of equipment during a true public health emergency (particularly a global one), and underscores one of the challenges to requiring self-monitoring of body temperature as a condition of entry to a college campus, i.e. it is likely unrealistic to expect accurate responses to required selfattestations of being fever and symptom-free, especially for students.

Overall, the sensitivity of temperature or symptoms screening in our study never rose above $40.5 \%$, and the best-performing quantitative temperature threshold had 
Table 2 Performance characteristics of potential indicators of SARS-CoV-2 infection

\begin{tabular}{|c|c|c|c|c|c|c|c|c|c|c|c|c|}
\hline & \multicolumn{2}{|c|}{$\begin{array}{l}\text { Temperature } \geq \\
100.4^{\circ} \mathrm{F}^{\mathrm{a}} \text { same } \\
\text { day as } \\
\text { specimen } \\
\text { collection }\end{array}$} & \multicolumn{2}{|c|}{$\begin{array}{l}\text { Temperature } \geq \\
99.7^{\circ} \mathrm{F}^{\mathrm{b}} \text { same } \\
\text { day as } \\
\text { specimen } \\
\text { collection }\end{array}$} & \multicolumn{2}{|c|}{$\begin{array}{l}\text { Temperature } \geq \\
98.7^{\circ} F^{c} \text { same } \\
\text { day as } \\
\text { specimen } \\
\text { collection }\end{array}$} & \multicolumn{2}{|c|}{$\begin{array}{l}\text { Temperature } \geq \\
99.7^{\circ} \mathrm{F} \text { same } \\
\text { day or any of } \\
3 \text { days prior to } \\
\text { specimen } \\
\text { collection }\end{array}$} & \multicolumn{2}{|c|}{$\begin{array}{l}\text { Self-report } \\
\text { fever } \\
\text { symptoms } \\
\text { (i.e., feeling } \\
\text { feverish) same } \\
\text { day as } \\
\text { specimen } \\
\text { collection }\end{array}$} & \multicolumn{2}{|c|}{$\begin{array}{l}\text { Self-report } \\
\text { COVID-19 } \\
\text { symptoms, in- } \\
\text { cluding fever } \\
\text { same day as } \\
\text { specimen } \\
\text { collection }\end{array}$} \\
\hline $\begin{array}{l}\text { Number of PCR positive results with } \\
\text { relevant data recorded (out of } 60 \\
\text { total) }\end{array}$ & \multicolumn{2}{|l|}{36} & \multicolumn{2}{|l|}{36} & \multicolumn{2}{|l|}{36} & \multicolumn{2}{|l|}{37} & \multicolumn{2}{|l|}{42} & \multicolumn{2}{|l|}{42} \\
\hline $\begin{array}{l}\text { Number of PCR negative results with } \\
\text { relevant data recorded (out of } 7612 \\
\text { total) }\end{array}$ & \multicolumn{2}{|l|}{4294} & \multicolumn{2}{|l|}{4294} & \multicolumn{2}{|l|}{4294} & \multicolumn{2}{|l|}{4487} & \multicolumn{2}{|l|}{5415} & \multicolumn{2}{|l|}{5415} \\
\hline $\begin{array}{l}\text { Number of people with } \mathrm{PCR} \text { positive } \\
\text { results who would have been } \\
\text { identified through this indicator }\end{array}$ & \multicolumn{2}{|l|}{$0 / 36$} & \multicolumn{2}{|l|}{$3 / 36$} & \multicolumn{2}{|l|}{$11 / 36$} & \multicolumn{2}{|l|}{$4 / 37$} & \multicolumn{2}{|l|}{$8 / 42$} & \multicolumn{2}{|l|}{$17 / 42$} \\
\hline \multirow{2}{*}{$\begin{array}{l}\text { Number of people with PCR negative } \\
\text { results who would have been } \\
\text { "flagged" per this indicator }\end{array}$} & \multicolumn{2}{|c|}{$4 / 4294$} & \multicolumn{2}{|c|}{$11 / 4294$} & \multicolumn{2}{|c|}{300 / 4294} & \multicolumn{2}{|c|}{$25 / 4487$} & \multicolumn{2}{|c|}{$17 / 5415$} & \multicolumn{2}{|c|}{$254 / 5415$} \\
\hline & $\begin{array}{l}\text { pt. } \\
\text { est. }\end{array}$ & $\begin{array}{l}(95 \% \\
\mathrm{Cl})\end{array}$ & $\begin{array}{l}\text { pt. } \\
\text { est. }\end{array}$ & $\begin{array}{l}(95 \% \\
\mathrm{Cl})\end{array}$ & $\begin{array}{l}\text { pt. } \\
\text { est. }\end{array}$ & $\begin{array}{l}(95 \% \\
\mathrm{Cl})\end{array}$ & $\begin{array}{l}\text { pt. } \\
\text { est. }\end{array}$ & $\begin{array}{l}(95 \% \\
\mathrm{Cl})\end{array}$ & $\begin{array}{l}\text { pt. } \\
\text { est. }\end{array}$ & $\begin{array}{l}(95 \% \\
\mathrm{Cl})\end{array}$ & $\begin{array}{l}\text { pt. } \\
\text { est. }\end{array}$ & $\begin{array}{l}(95 \% \\
\mathrm{Cl})\end{array}$ \\
\hline Sensitivity & $0.0 \%$ & $\begin{array}{l}(0.0- \\
9.7 \%)\end{array}$ & $8.3 \%$ & $\begin{array}{l}(1.8- \\
22.5 \%)\end{array}$ & $30.6 \%$ & $\begin{array}{l}(16.3- \\
48.1 \%)\end{array}$ & $10.8 \%$ & $\begin{array}{l}(3.0- \\
25.4 \%)\end{array}$ & $19.0 \%$ & $\begin{array}{l}(8.6- \\
34.1 \%)\end{array}$ & $40.5 \%$ & $\begin{array}{l}(25.6- \\
56.7 \%)\end{array}$ \\
\hline Specificity & $99.9 \%$ & $\begin{array}{l}(99.8- \\
100 \%)\end{array}$ & $99.7 \%$ & $\begin{array}{l}(99.5- \\
99.9 \%)\end{array}$ & $93.0 \%$ & $\begin{array}{l}(92.2- \\
93.8 \%)\end{array}$ & $99.4 \%$ & $\begin{array}{l}(99.2- \\
99.6 \%)\end{array}$ & $99.7 \%$ & $\begin{array}{l}(99.5- \\
99.8 \%)\end{array}$ & $95.3 \%$ & $\begin{array}{l}\text { (94.7- } \\
95.9 \%)\end{array}$ \\
\hline PPV $^{e}$ & $0.0 \%$ & $\begin{array}{l}(0.0- \\
59.4 \%)\end{array}$ & $21.4 \%$ & $\begin{array}{l}(7.4- \\
48.6 \%)\end{array}$ & $3.5 \%$ & $\begin{array}{l}(2.2- \\
5.8 \%)\end{array}$ & $13.8 \%$ & $\begin{array}{l}(5.6- \\
30.6 \%)\end{array}$ & $32.0 \%$ & $\begin{array}{l}(17.8- \\
50.9 \%)\end{array}$ & $6.3 \%$ & $\begin{array}{l}(4.4- \\
9.0 \%)\end{array}$ \\
\hline$N^{\prime} V^{f}$ & $99.2 \%$ & $\begin{array}{l}(99.1- \\
99.3 \%)\end{array}$ & $99.2 \%$ & $\begin{array}{l}(99.1- \\
99.3 \%)\end{array}$ & $99.4 \%$ & $\begin{array}{l}(99.2- \\
99.5 \%)\end{array}$ & $99.3 \%$ & $\begin{array}{l}(99.2- \\
99.3 \%)\end{array}$ & $99.4 \%$ & $\begin{array}{l}(99.3- \\
99.5 \%)\end{array}$ & $99.5 \%$ & $\begin{array}{l}\text { (99.4- } \\
99.6 \%)\end{array}$ \\
\hline Fisher's Exact test ${ }^{g} p$-value & - & & 0.0002 & & $<0.000$ & & $<0.000$ & & $<0.000$ & & $<0.000$ & \\
\hline
\end{tabular}

${ }^{a}$ This was the threshold used for triggering additional testing during the study

b This is one degree above what is conventionally considered "normal" body temp

${ }^{c}$ This is one degree above the mean temperature for our study participants over the full study period $\left(\operatorname{mean}=97.6^{\circ} \mathrm{F}\right.$ )

${ }^{d}$ For purposes of this analysis, participants were considered "symptomatic" if on their daily survey they reported dry cough, coughing up mucus, fever, sweats, chills, sore throat, difficulty breathing, wheezing, shortness of breath, loss of sense of taste, loss of sense of smell, or at least 3 symptoms from a list of 35 symptoms associated with COVID-19 and other illnesses (see Supplemental Table 1)

e PPV = Positive predictive value

${ }^{f} \mathrm{NPV}=$ Negative predictive value

${ }^{g}$ Fisher's Exact test for independence was used, given rare exposure and rare outcome. This tested the null hypothesis that there was no difference in SARS-CoV2 infection for people who would have been prohibited entry to campus as a result of screening for fever using the strategy in question, and those who would be permitted entry to campus

a sensitivity of only $30.6 \%$, but considered fever to be anything at or above $98.7^{\circ} \mathrm{F}$, which would be considered normal body temperature in most settings and resulted in a positive predictive value of only $3.5 \%$ (95\% CI $2.2-$ $5.8 \%)$. These findings align well with recently published results from an Australian hospital, where fever $\geq 100.4^{\circ} \mathrm{F}$ was only detected in 16 of 86 patients testing positive for SARS-CoV-2 over a 2-month period (sensitivity of $19,95 \%$ CI 11-28\%), when using a variety of inhospital temperature measurement methods, mostly with temporal thermometers [38]. While their sensitivity using this fever threshold was higher than we observed in this study, this is unsurprising given that these were among hospital patients, not people who were mostly feeling well at time of testing. While the specificity of the strategies tested in our study was reasonably good
( $>93 \%$ in all cases), this study was conducted during the summer months, well before the typical influenza season in the San Francisco Bay Area. Specificity of temperature monitoring for SARS-CoV-2 can be expected to worsen in the fall and winter months, when the prevalence of influenza-like illness for reasons other than infection with SARS-CoV-2 is substantially increased.

There were significant associations between measured body temperature and PCR test results in longitudinal mixed models when controlling for individual variation in body temperatures; however, these regression models were designed to account for within-person variation in baseline temperature that is not scalable to real-life monitoring strategies, and does not apply to the most common temperature monitoring policies, which use dichotomous fever thresholds for permitting building 
entry or triggering symptoms-based SARS-CoV-2 testing, rather than a more sophisticated and individualized algorithm. Further, the performance of self-reported qualitative fever symptoms ("feeling feverish") in this study suggests that daily quantitative temperature monitoring may not offer additional protection as a screening measure to prevent SARS-CoV-2 transmission on a college campus. Research by others that has found substantial measurement error with regard to body temperature [26] bolsters the idea that qualitative self-report may be a preferable strategy.

Our study had a number of limitations. First, temperature data included here could be inaccurate for multiple reasons, including error using the thermometer or reporting error, such as participants not recording their temperature despite taking it or recording the temperature incorrectly. However, such limitations also apply to any scaled, non-research campus-level system for temperature monitoring. Second, while participants were asked to take their temperature in the morning, we did not control for time of day in this analysis, because there was substantial information bias in the daily survey timestamp (i.e. some participants anecdotally reported taking their temperature in the morning as requested but completing the survey at a later time). This may have made us less likely to detect fevers among our participants [24]; however, since many school or work-based temperature screenings likely take place in the morning, this limitation would also apply to any scaled campus-level temperature screening system. Similarly, we did not control for differences in thermometer type in our analysis, given that the large majority of participants had an oral thermometer, despite the fact that type of thermometer used is related to mean body temperature measurements [39]. However, this too is a limitation that would apply in real-life application of any campus-level temperature monitoring strategy. Third, individual basal temperature is known to vary by fertility cycle for women not taking hormones [40]; however, we did not collect information about birth control or other hormone use during this study, so could not account for this in our analysis. A sensitivity analysis (not shown) stratifying our adjusted regression model by sex showed nearly identical results for women compared to the overall study population, suggesting that this hormonal temperature variation was not an important factor. Fourth, our results related to feasibility and acceptability of temperature monitoring were likely biased by the incentives provided to participants to encourage daily monitoring, as well as the enthusiasm for such activities among the type of person who would enroll in an intensive study of this nature, compared to a general campus population.
Finally, it is possible that some participants had SARSCoV-2 infection that was not detected by PCR testing, and therefore our effectiveness results may be biased in an unpredictable direction.

\section{Conclusions}

Given the popularity of temperature monitoring as a non-invasive measure for rapid screening for SARS$\mathrm{CoV}-2$ infection before allowing students or employees access to college campuses, workplaces, or congregate venues, our findings offer important insight into the insufficiency of such methods on college campuses, despite widespread adherence to and acceptability of daily temperature monitoring strategies.

In concordance with evidence from prior global pandemics $[6,8-11]$, our findings suggest temperature screening using dichotomous fever thresholds during the COVID-19 pandemic may be little more than "security theater" [41]. This term, largely attributed to computer security expert Bruce Schneier, describes measures that provide a sense of security, despite having no actual positive impact on security. Temperature monitoring strategies may be a rational response to community calls for action, even if those demands for action are based on inaccurate or outdated information about the risks and effective strategies for COVID-19 mitigation [42, 43]. Other strategies to disinfect or otherwise prevent fomite transmission have also been implemented during the COVID-19 pandemic, often at great cost and with questionable preventative benefit [44-46]. Millions of dollars are invested in similar "security theater" measures each year in the United States, from radio-frequency identification (RFID) ankle bracelets to prevent hospital newborn abductions to removing shoes and prohibiting liquids above $3.4 \mathrm{oz}$ at airport security $[47,48]$, in order to reassure the public that sufficient action is being taken in the face of a serious threat. Measures like this can have some benefit; namely, some individuals with SARS-CoV-2 would undoubtedly be detected by temperature screening measures and prevented from transmitting the virus to others. Further, routine temperature monitoring can reassure members of a campus community or workplace that those in charge care about their health and are taking the pandemic seriously. Yet an ineffective action can be harmful, if people believe that because temperature screening measures are in effect they are safe, and therefore other measures to prevent spread of SARS-CoV-2 - such as wearing a face covering and practicing social distancing - are not taken seriously [49].

Further attention is needed to the benefits and drawbacks of various strategies to detect and prevent transmission of SARS-CoV-2 on college campuses and in similar close-knit communities, to ensure the 
community is fully aware of the practical and behavioral implications of any strategies employed. Colleges may want to consider using qualitative measures for selfreport of feverishness as a symptom rather than attempting quantitative temperature monitoring, and focus resources on additional strategies known to prevent SARS$\mathrm{CoV}-2$ transmission, such as low-barrier access to SARS-CoV-2 testing without requiring disclosure of specific risks or symptoms [50], rather than relying on temperature screening or self-attestations of good health as a condition of campus access.

\section{Abbreviations \\ Cl: Confidence Interval; COVID-19: Coronavirus Disease 2019; \\ CPHS: Committee for the Protection of Human Subjects; FDA: Food and Drug Administration; IQR: Interquartile Ratio; NPV: Negative Predictive Value: PCR: Polymerase Chain Reaction; PPV: Positive Predictive Value; \\ REDCap: Research Electronic Data Capture; RFID: Radio-Frequency Identification; SARS: Severe Acute Respiratory Syndrome; SARS-CoV-2: Severe Acute Respiratory Syndrome Coronavirus 2; UHS: University Health Services}

\section{Supplementary Information}

The online version contains supplementary material available at https://doi. org/10.1186/s12889-021-11697-6.

Additional file 1: Supplemental Table 1. List of Symptoms Asked on Participant Daily Surveys. Supplemental Table 2. Answers to the Endline survey question "What was the most difficult or frustrating component of the study for you?". Supplemental Figure 1. Number of surveys completed per day, all participants. Supplemental Figure 2. Number of surveys completed per day, students only (A) and faculty, staff, or essential workers only (B).

\section{Acknowledgments}

This work could not have been done without our hard-working graduate student researchers, who worked all summer at the specimen collection site and responded to participant questions and concerns about thermometers: Mariah De Zuzuarregui, Darren Frank, Sarah Gomez, Ariel Muñoz, Ruben Prado, Lawrence Tello, Emily Wang, and Sabrina Williamson. We also wish to thank our collaborators at UC Berkeley's University Health Services, where specimen collection and thermometer pickup took place, including but not limited to: Judith Sansone, Melody Heller, Holly Stern, Tyler Crooks, Desi Gallardo, Jeff Kreutzen, Rebecca Stephenson, Lisa Polley, and Melissa Hennings; and our collaborators at the Innovative Genomics Institute Testing Consortium, including Fyodor D. Urnov, Jennifer A. Doudna, Alexandra M. Amen, Kerrie W. Barry, John M. Boyle, Cara E. Brook, Seunga Choo, L.T. Cornmesser, David J. Dilworth, Alexander J. Ehrenberg, Indro Fedrigo, Skyler E. Friedline, Thomas G.W. Graham, Ralph Green, Jennifer R. Hamilton, Ariana Hirsh, Megan L. Hochstrasser, Dirk Hockemeyer, Netravathi Krishnappa, Azra Lari, Hanqin Li, Enrique Lin-Shiao, Tianlin Lu, Elijah F. Lyons, Kevin G. Mark, Lisa Argento Martell, A. Raquel O. Martins, Patrick S. Mitchell, Erica A. Moehle, Christine Naca, Divya Nandakumar, Elizabeth O'Brien, Derek J. Pappas, Kathleen Pestal, Diana L. Quach, Benjamin E. Rubin, Rohan Sachdeva, Elizabeth C. Stahl, Abdullah Muhammad Syed, I-Li Tan, Amy L. Tollner, Connor A. Tsuchida, C. Kimberly Tsui, Timothy K. Turkalo, M. Bryan Warf, Oscar N. Whitney, and Lea B. Witkowsky. Last but not least, thanks to the specialists in Supply Chain Management at UC Berkeley who managed to find thousands of low-cost thermometers during a pandemic, particularly Stacey Templeman.

\section{Authors' contributions}

SF, LH, LP, MP, and AR led study conception and design; AH, GN, and SD oversaw components of study implementation; SF led the analysis with important contributions from $Y L, L H$, and MP; SF wrote the first manuscript draft; and SF, LH, LP, YL, GN, MP, and AR substantively revised the manuscript. The author(s) read and approved the final manuscript.

\section{Funding}

This study was funded through private donations from University of California, Berkeley alumni and families of current students. Private donors had no role in the design of the study, nor collection, analysis, or interpretation of data, nor writing the manuscript.

\section{Availability of data and materials}

The datasets used and/or analyzed during the current study are available from the corresponding author on reasonable request.

\section{Declarations}

Ethics approval and consent to participate

This research and all relevant protocols were approved by the UC Berkeley Committee for the Protection of Human Subjects (CPHS), protocols \#202006-13,349 (essential workers), \#2020-05-13,261 (students), and \#2020-0413,238 (faculty/staff). All methods were carried out in accordance with relevant guidelines and regulations. Informed consent was obtained from all study participants before any study procedures occurred.

\section{Consent for publication}

Not applicable.

\section{Competing interests}

The authors declare that they have no competing interests.

\section{Author details}

${ }^{1}$ School of Public Health, Division of Epidemiology and Biostatistics, University of California, Berkeley, 2121 Berkeley Way \# 5302, Berkeley, CA 94720 , USA. ${ }^{2}$ Facente Consulting, Richmond, CA, USA. ${ }^{3}$ University Health Services, University of California Berkeley, Berkeley, CA, USA. ${ }^{4}$ Innovative Genomics Institute, University of California Berkeley, Berkeley, CA, USA.

Received: 28 April 2021 Accepted: 29 August 2021

Published online: 16 September 2021

\section{References}

1. Lake MA. What we know so far: COVID-19 current clinical knowledge and research. Clin Med. 2020;20(2):124-7. https://doi.org/10.7861/clinmed.2019coron.

2. Wei WE. Presymptomatic transmission of SARS-CoV-2 - Singapore, January 23-march 16, 2020. Morb Mortal Wkly Rep. 2020;69(14):411-5. https://doi. org/10.15585/mmwr.mm6914e1.

3. Kimball A, Hatfield KM, Arons M, James A, Taylor J, Spicer K, et al. Asymptomatic and Presymptomatic SARS-CoV-2 infections in residents of a long-term care skilled nursing facility - King County, Washington, march 2020. Morb Mortal Wkly Rep. 2020;69(13):377-81. https://doi.org/10.15585/ mmwr.mm6913e1.

4. Moriarty LF, Plucinski MM, Marston BJ, Kurbatova EV, Knust B, Murray EL et al. Public health responses to COVID-19 outbreaks on cruise ships worldwide, February-march 2020. Morb Mortal Wkly Rep. 2020;69(12):34752. https://doi.org/10.15585/mmwr.mm6912e3.

5. Byambasuren O, Cardona M, Bell K, Clark J, McLaws M-L, Glasziou P. Estimating the extent of asymptomatic COVID-19 and its potential for community transmission: systematic review and meta-analysis. MedRxiv. 2020;2020(05):10.20097543.

6. Tay MR, Low YL, Zhao X, Cook AR, Lee VJ. Comparison of infrared thermal detection systems for mass fever screening in a tropical healthcare setting. Public Health. 2015;129(11):1471-8. https://doi.org/10.1016/j.puhe.2015.07. 023.

7. Frieden TR, Damon IK. Ebola in West Africa-CDC's role in epidemic detection, control, and prevention. Emerg Infect Dis. 2015;21(11):1897-905. https://doi.org/10.3201/eid2111.150949.

8. Bitar D, Goubar A, Desenclos JC. International travels and fever screening during epidemics: a literature review on the effectiveness and potential use of non-contact infrared thermometers. Euro Surveill. 2009;14(6):19115.

9. Canadian Agency for Drugs and Technologies in Health. Mass Thermography Screening for Infection and Prevention: A Review of the Clinical Effectiveness. Ottawa: Canadian Agency for Drugs and Technologies in Health; 2014 
10. Liu CC, Chang RE, Chang WC. Limitations of forehead infrared body temperature detection for fever screening for severe acute respiratory syndrome. Infect Control Hosp Epidemiol. 2004;25(12):1109-11. https://doi. org/10.1086/502351.

11. Mouchtouri VA, Christoforidou EP, An der Heiden M, et al. Exit and Entry Screening Practices for Infectious Diseases among Travelers at Points of Entry: Looking for Evidence on Public Health Impact. Int J Environ Res Public Health. 2019;16(23). https://doi.org/10.3390/ijerph16234638.

12. Normile D. Airport screening is largely futile, research shows. Science. 2020; 367(6483):1177-8. https://doi.org/10.1126/science.367.6483.1177.

13. Chang JC, Chen YH, Lin MC, et al. Emergency department response to COVID-19 outbreak with a fever screening station and "graded approach" for isolation and testing. J Chin Med Assoc. 2020;83(11):997-1003.

14. Chung $Y T$, Yeh $C Y$, Shu YC, et al. Continuous temperature monitoring by a wearable device for early detection of febrile events in the SARS-CoV-2 outbreak in Taiwan, 2020. J Microbiol Immunol Infect. 2020;53(3):503-4. https://doi.org/10.1016/j.jmii.2020.04.005.

15. Bwire GM, Paulo LS. Coronavirus disease-2019: is fever an adequate screening for the returning travelers? Trop Med Health. 2020;48(1):14. https://doi.org/10.1186/s41182-020-00201-2.

16. U.S. Food and Drug Administration. Non-contact Temperature Assessment Devices During the COVID-19 Pandemic. 2020. https://www.fda.gov/medica I-devices/coronavirus-covid-19-and-medical-devices/non-contact-tempera ture-assessment-devices-during-covid-19-pandemic. Accessed 7 Sept 2020.

17. Environmental Health \& Safety, University of Washington. University of Washington Guidance for Symptom Monitoring for COVID-19. Seattle: University of Washington; 2020. https://www.ehs.washington.edu/system/ files/resources/guidance-symptom-monitoring-COVID-19.pdf. Accessed 10 Oct 2020.

18. University of Pittsburgh at Greensburg. Requirements for Campus Access During COVID-19. 2020. https://www.greensburg.pitt.edu/covid-19/campusrequirements. Accessed 10 Oct 2020.

19. Returning to Campus: Employee Self-Assessment Requirements and Attestation. Louisville: University of Louisville; 2020. https://louisville.edu/ research/covid19resources/employee-self-assessment-form-pdf. Accessed 10 Oct 2020.

20. New Mandate: All UCSF personnel must complete in-person or online screener before entering UCSF hospitals. 2020. https://www.ucsfhealth.org/ daily-health-screening. Accessed 10 Oct 2020.

21. Berkeley Research. COVID-19 Research resources: before returning to campus. 2020. https://vcresearch.berkeley.edu/covid19/before-returning. Accessed 10 Oct 2020.

22. Centers for Disease Control and Prevention (CDC). Definitions of Symptoms for Reportable IIInesses. 2020. https://www.cdc.gov/quarantine/air/reporting deaths-illness/definitions-symptoms-reportable-illnesses.html.

23. Protsiv M, Ley C, Lankester J, Hastie T, Parsonnet J. Decreasing human body temperature in the United States since the industrial revolution. eLife. 2020; 9. https://doi.org/10.7554/eLife.49555.

24. Harding C, Pompei F, Bordonaro SF, McGillicuddy DC, Burmistrov D, Sanchez LD. Fever incidence is much lower in the morning than the evening: Boston and US National Triage Data. West J Emerg Med. 2020; 21(4):909-17. https://doi.org/10.5811/westjem.2020.3.45215.

25. Harding C, Pompei F, Bordonaro SF, McGillicuddy DC, Burmistrov D, Sanchez LD. The daily, weekly, and seasonal cycles of body temperature analyzed at large scale. Chronobiol Int. 2019;36(12):1646-57. https://doi. org/10.1080/07420528.2019.1663863.

26. Sund-Levander M, Grodzinsky E, Loyd D, Wahren LK. Errors in body temperature assessment related to individual variation, measuring technique and equipment. Int J Nurs Pract. 2004;10(5):216-23. https://doi. org/10.1111/j.1440-172X.2004.00483.x.

27. Obermeyer Z, Samra JK, Mullainathan S. Individual differences in normal body temperature: longitudinal big data analysis of patient records. BMJ. 2017;359:j5468. https://doi.org/10.1136/bmj.j5468.

28. Hu JC. The Dawn of the COVID self-attestation. Slate. 2020. https://slate. com/technology/2020/05/self-attestation-covid19-symptoms-lyft.html.

29. von Elm E, Altman DG, Egger M, Pocock SJ, Gøtzsche PC, Vandenbroucke $J P$. The strengthening the reporting of observational studies in epidemiology (STROBE) statement: guidelines for reporting observational studies. Epidemiology. 2007;18(6):800-4. https://doi.org/10.1097/EDE.0b013 e3181577654.
30. Harris PA, Taylor R, Thielke R, Payne J, Gonzalez N, Conde JG. Research electronic data capture (REDCap)--a metadata-driven methodology and workflow process for providing translational research informatics support. J Biomed Inform. 2009:42(2):377-81. https://doi.org/10.1016/j.jbi.2008.08.010.

31. Harris PA, Taylor R, Minor BL, Elliott V, Fernandez M, O'Neal L, et al. The REDCap consortium: Building an international community of software platform partners. J Biomed Inform. 2019;95:103208. https://doi.org/10.1016/ j.jbi.2019.103208.

32. Gardner B. A review and analysis of the use of 'habit' in understanding, predicting and influencing health-related behaviour. Health Psychol Rev. 2015;9(3):277-95. https://doi.org/10.1080/17437199.2013.876238.

33. Mantzari E, Vogt F, Shemilt I, Wei Y, Higgins JP, Marteau TM. Personal financial incentives for changing habitual health-related behaviors: a systematic review and meta-analysis. Prev Med. 2015;75:75-85. https://doi. org/10.1016/j.ypmed.2015.03.001.

34. Amen AM, Barry KW, Boyle JM, et al. Blueprint for a pop-up SARS-CoV-2 testing lab. Nat Biotechnol. 2020;38(7):791-7. https://doi.org/10.1038/s41587020-0583-3.

35. Clopper CJ, Pearson ES. The use of confidence of fiducial limits illustrate in the case of the binomial. Biometrika. 1934;26(4):404-13. https://doi.org/10.1 093/biomet/26.4.404

36. Mercaldo ND, Lau KF, Zhou XH. Confidence intervals for predictive values with an emphasis to case-control studies. Stat Med. 2007;26(10):2170-83. https://doi.org/10.1002/sim.2677.

37. Schaarschmidt F. bdpv: Inference and Design for Predictive Values in Diagnostic Tests. The Comprehensive R Archive Network (CRAN); 2019.

38. Mitra B, Luckhoff C, Mitchell RD, O'Reilly GM, Smit V, Cameron PA. Temperature screening has negligible value for control of COVID-19. Emerg Med Australasia. 2020;32(5):867-9. https://doi.org/10.1111/1742-6723.13578.

39. Geneva CB II, Fazili T, Javaid W. Normal Body Temperature: A Systematic Review. Open Forum Infect Dis. 2019;6(4):ofz032

40. Stephenson LA, Kolka MA. Esophageal temperature threshold for sweating decreases before ovulation in premenopausal women. J Appl Physiol (1985). 1999;86(1):22-8.

41. Schneier B. Beyond fear: thinking sensibly about security in an uncertain world. New York: Springer; 2006.

42. Turner BM, Schley DR. The anchor integration model: a descriptive model of anchoring effects. Cogn Psychol. 2016;90:1-47. https://doi.org/10.1016/j. cogpsych.2016.07.003

43. Quattrone GA. Overattribution and unit formation: when behavior engulfs the person. J Pers Soc Psychol. 1982;42(4):593-607. https://doi.org/10.1037/ 0022-3514.42.4.593.

44. Kemper CA. Hygiene Theater. Internal Med Alert. 2020;42(18). https://www. reliasmedia.com/articles/146857-hygiene-theater.

45. Fisher M. Even as cases plummet, 'hygiene theater' persists. Wash Post. 2021:A.1.

46. Goldman E. Exaggerated risk of transmission of COVID-19 by fomites. Lancet Infect Dis. 2020;20(8):892-3. https://doi.org/10.1016/S1473-3099(20)30561-2.

47. Schneier B. The Psychology of Security. Berlin: Springer Berlin Heidelberg; 2008. p. 50-79.

48. Schneier B. In Praise of Security Theater. Wired. 2007.

49. Hamblin J. Paging Dr. Hamblin: Everyone wants to check my temperature. The Atlantic. 2020

50. Paltiel AD, Zheng A, Walensky RP. Assessment of SARS-CoV-2 Screening Strategies to Permit the Safe Reopening of College Campuses in the United States. JAMA Network Open. 2020;3(7):e2016818-e.

\section{Publisher's Note}

Springer Nature remains neutral with regard to jurisdictional claims in published maps and institutional affiliations. 